\title{
Managing Small Ureteral Stones: A Retrospective Study on Follow-Up, Clinical Outcomes and Cost-Effectiveness of Conservative Management vs. Early Surgery
}

\author{
Aristeidis Alevizopoulos $^{\mathrm{a}} \quad$ Dimitrios Zosimas $^{\mathrm{b}} \quad$ Lamprini Piha $^{\mathrm{c}}$ \\ Milad Hanna $^{d} \quad$ Konstantinos Charitopoulos ${ }^{d}$

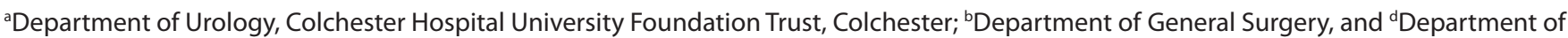

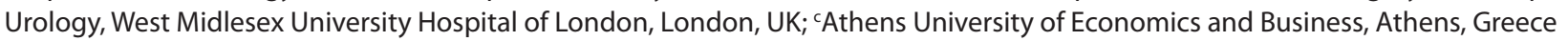

\section{Key Words}

Conservative management $\cdot$ Cost-effective $\cdot$ Tamsulosin $•$

Ureteral calculus • Urolithiasis

\begin{abstract}
Introduction: The management of ureteral calculi has evolved over the past decades with the advent of new surgical and medical treatments. The current guidelines support conservative management as a possible approach for ureteral stones sized $=10 \mathrm{~mm}$. Objectives: We purport to follow the natural history of ureteral stones managed conservatively in this retrospective study, and attempt to ascribe an estimated health-care and cost-effectiveness, from presentation to time of being stone-free. Materials and methods: 192 male and female patients with a single ureteral stone sized $=10 \mathrm{~mm}$ were included in this study. The clinical and cost-related outcome was analyzed for different stone sizes (0-4, 4-6 and 6-10 mm). The effectiveness of selected follow-up (FU) scans was also analyzed. Results: Stone size was found to be related to the degree of hydronephrosis and to the likelihood of need for a surgical management. Conservative management was found to be clinically effective, as $88 \%$ of the patients did not require surgery for their stone. $96.1 \%$ of the patients with a stone $0-4 \mathrm{~mm}$ managed to ex-
\end{abstract}

\section{KARGER}

Fax +4161306 1234

E-Mail karger@karger.ch

www.karger.com
(C) 2015 S. Karger AG, Basel

1015-9770/14/0091-0036\$38.00/0

Accessible online at:

www.karger.com/cur pel their ureteral stone. Bigger ureteral stones were found to be more costly. The cost-effectiveness of the single FU scans was found to be related to their efficiency, while the global cost-effectiveness of conservative management vs. early surgery was higher for smaller stones ( 26.8 vs. $17.32 \%$ for stones 0-4 vs. 6-10 mm). Conclusion: Conservative management is clinically effective with a significant cost-benefit, particularly for the subgroup of stones sized 0-4 mm, where a need for FU scans is in dispute. Copyright $\odot 2015 \mathrm{~s}$. Karger AG, Basel

\section{Introduction}

The management of ureteral calculi has evolved over the past decades with the advent of extracorporeal shockwave lithotripsy, the development of ureteroscopic technology and the introduction of medical expulsive therapy (MET). Patients with ureteral calculi $\leq 10 \mathrm{~mm}$ in diameter, have a high likelihood of spontaneous stone expulsion, and the current joint EAU/AUA guidelines offer the option of an initial conservative approach with the use of MET and close follow-up [1]. 
Table 1. Exclusion criteria

\begin{tabular}{ll}
\hline No. & Exclusion criteria \\
\hline 1 & $\begin{array}{l}\text { Patients with delayed ( }>90 \text { days) or suboptimal follow up } \\
2\end{array}$ \\
$\begin{array}{l}\text { Patients with multiple comorbidities or on multiple medi- } \\
\text { cation; patients with reduced mobility }\end{array}$ \\
3 & $\begin{array}{l}\text { Patients aged }<18 \text { years or }>80 \text { years } \\
4\end{array}$ \\
$\begin{array}{l}\text { Patients with multiple }(>1) \text { ureteral stones or with previous } \\
\text { surgery for ureteral stones }\end{array}$ \\
$\begin{array}{l}\text { Patients admitted with obstructive urosepsis } \\
6\end{array}$ \\
$\begin{array}{l}\text { Patients who changed management due to non medical rea- } \\
\text { sons (social/professional etc.) }\end{array}$ \\
$\begin{array}{l}\text { Patients with NSAID allergy/intolerance; patients who did } \\
\text { not conform with given treatment }\end{array}$ \\
\hline
\end{tabular}

In the process of making a decision whether a patient is eligible or not for conservative management, radiologic parameters (stone size, degree of dilatation, stone position) as well as subjective parameters such as pain level, can contribute to the final decision for active treatment or surveillance. There is no strong evidence on how the stone size can be related to the pain level, while there is some evidence which correlates the type and level of pain with the stone position [2]. Larger stones understandably seem to be associated to a greater degree of hydronephrosis [3].

Hitherto, studies on MET have mainly focused on the use of $\alpha 1$ blockers, calcium channel antagonists and corticosteroids. The current evidence favors the $\alpha 1$-blockers, with tamsulosin being the most tested one [4-7]. MET seems to be mainly effective on stones $5-10 \mathrm{~mm}$ in size $[5,8]$, as stones $<5 \mathrm{~mm}$ have more than $65 \%$ of chances to be expelled without additional treatment [1]. The previous recommendation of MET only for distal ureteral stones, has been recently extended, with a level of evidence $1 \mathrm{~B}$, on the management of proximal ureteral stones [9]. Though, a recent blind randomized placebocontrolled trial debates the usefulness of Tamsulosin or nifedipine in promoting the stone passage [10].

With regards to the correct radiologic follow-up of these patients, there is a lack of consensuses in terms of timing and type of scan that should be performed [1114]. While the recommendations from the EAU guidelines currently favor the use of non-contrast computed tomography for the diagnostic approach of the acute flank pain, there are not any current recommendations on how to follow-up ureteral stone patients, managed conservatively. There is some evidence on whether conservative management of small stones can compromise the renal function irreversibly. Most of the relevant evidence was based on animal models, and a complete reversal ureteral obstruction. Thus, the out coming evidence is controversial and biased [15-19].

Regarding the cost effectiveness of stone management, the current research has focused to the different surgical approaches [20-27].There has been surprisingly little research about the cost effectiveness of conservative management vs early surgical removal $[28,29]$.The out coming evidence from these studies is weak, as even patients with stones of $>10 \mathrm{~mm}$ were included, while in the most recent study, female patients were excluded.

\section{Objectives}

We purport to follow the natural history of ureteral stones managed conservatively in this retrospective study, and attempt to ascribe an estimated health-care and cost-effectiveness, from presentation to time of being stone-free.

\section{Material and Methods}

\section{Data/Population}

This is a retrospective analysis of our hospital's rapid access stone clinic patient register, from January 2010 until March 2012. Out of an initial pool of 924, 192 male and female patients fulfilled our inclusion criteria. All selected patients had a single ureteral stone, sized $\leq 10 \mathrm{~mm}$ of maximum diameter, with or without concomitant renal stones, and had opted for conservative management of their ureteral stone. The selected patients were started on MET with tamsulosin $0.4 \mathrm{mg}$ once daily and regular painkillers including NSAID as required, immediately after they were diagnosed with the ureteral stone. The included patients were all diagnosed, after they had developed an episode of renal colic, and were all initially assessed in our hospital's accident \& emergency (A \& E) department. As per our Trust's renal colic protocol, the diagnostic assessment of all colic patients in A \& E was done with an unenhanced CT kidneys ureters and bladder (KUB). If a ureteral stone was identified, MET was prescribed by the A \& E team, while the patients were referred to our rapid access stone clinic, and reviewed by a urology consultant within 10 days. The pros and cons of MET vs early surgical removal or extracorporeal shockwave lithotripsy were explained to all selected patients with small ureteral stones. The patients who opted for initial conservative management were included in our sample. The exclusion criteria are summarized in table 1.

We decided that the best way to investigate on the pain perceived by the patients under the current set up was to study the number of A \& E re-attendances, due to colic pain.

\section{Follow-up}

All selected patients were followed-up for their ureteral stone, with either an ultrasound scan or other scans [x-ray kidneys ureters and bladder, intravenous urogram and occasionally, where necessary, a CT KUB]. 
Table 2. Ureteral stone size demografics

\begin{tabular}{llll}
\hline Size $(\mathrm{mm})$ & Frequency $(\mathrm{n})$ & Percentage $(\%)$ & $\begin{array}{l}\text { Cumulative } \\
\text { percentage }(\%)\end{array}$ \\
\hline $0-3.99$ & 53 & 27.6 & 27.6 \\
$4-5.99$ & 82 & 42.7 & 70.3 \\
$6-10$ & 57 & 29.7 & 100 \\
Total & 192 & 100 & - \\
\hline
\end{tabular}

The choice of the type of follow-up scan and the waiting intervals until this was performed were based on the stone features (position, size, radio-opaque or not, hydronephrosis). Patients with small degree of hydronephrosis, small level of pain and good renal function had usually more delayed follow-up (FU) scans, while in some cases where the stone was well evident in the X-ray KUB, this was our only follow-up scan. Occasionally, a repeat CT KUB was requested, when the pre-selected follow-up scan was not adequate.

Our target was to not postpone the follow-up scan for more than 6 weeks, even though some patients had to be re-scanned later than this. We excluded patients whose follow-up was after 180 days for whatever reason.

\section{Surgical Procedure}

Some of our patients required surgery (elective lithotripsy or stenting) during their follow-up, either because of the stone persistence on the follow-up scans, or frequent colic, or a deterioration of their renal function

\section{Parameters Analyzed}

The patients were characterized by gender, age, stone size, number of additional renal stones, and cost per single category. We divided the ureteral stones based on their size $(0-4,4-6$ and $6-10 \mathrm{~mm})$. The degree of dilatation due to the presence of the ureteral stone was grouped according to the radiological criteria of the CT KUB in none, mild, moderate and severe. Based on the number of stones found on the CT KUB, the patients were divided in 2 groups: a group with only one ureteral stone and a group with additional renal stones.

\section{Statistical Analysis}

All analyses were conducted using the SPSS 20 statistical software. Univariate analyses were conducted for basic statistical results such as frequencies of nominal variables and mean values of scale ones. Multivariate analyses were also conducted in order to test the relationship between different but relevant variables of interest. Depending on the variable type under investigation, these multivariate analyses included crosstabulation, bivariate correlation analysis and means-comparison with either one-way analysis of variance or independent samples t-test analysis. All results reported are statistically significant at the 0.05 level or less and can be therefore considered to be valid for the population as well.

\section{Cost Analysis}

In order to evaluate the cost-effectiveness of MET, we decided to include in our study only the individual costs of the diagnostic and follow-up scans, and those of the individual surgical opera-

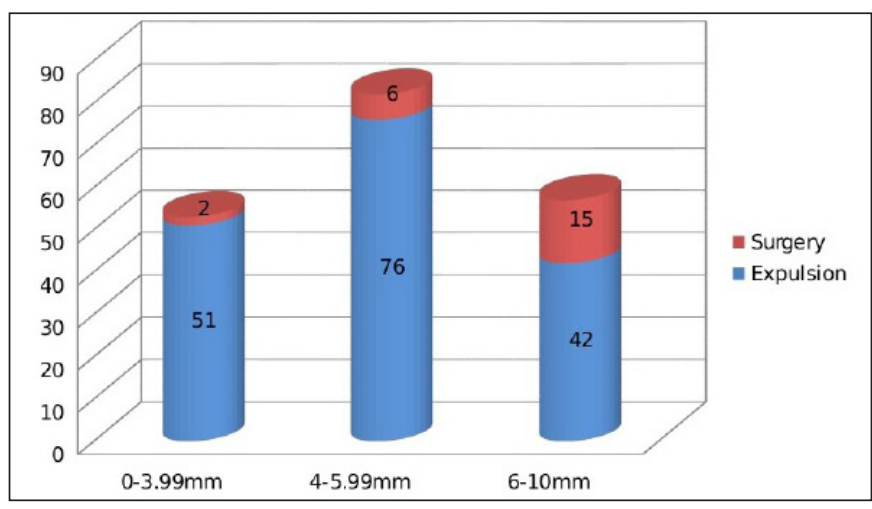

Fig. 1. Ureteral stone size*clinical outcome-crosstabulation

Table 3a. Follow up cost-Duncan ${ }^{\mathrm{a}, \mathrm{b}}$

\begin{tabular}{lllllllll}
\hline & \multicolumn{1}{c}{ Subset for alpha $=0.05$} \\
\hline Scan method & 0 & 0 & 1 & 2 & 3 & 4 & 5 & 6 \\
IVU & 4 & 0 & 0 & & & & & \\
X-ray KUB & 46 & 0 & 0 & & & & & \\
US KUB & 106 & 0 & & 0 & & & & \\
X-ray KUB/US KUB & 9 & 0 & & & 0 & & & \\
CT KUB & 17 & 0 & & & & 0 & & \\
X-ray KUB/CT KUB & 5 & 2605 & & & & & 0 & \\
US KUB/CT KUB & 5 & 2605 & & & & & & 0 \\
Sig. & & & 786 & 1000 & 455 & 1000 & 1000 & 1000
\end{tabular}

KUB $=$ kidneys ureters and bladder. Means for groups in homogeneous subsets are displayed. a: Uses Harmonic Mean Sample Size = 5,585; b: The group sizes are unequal. The harmonic mean of the group sizes is used. Type I error levels are not guaranteed.

tions, based on the private patient coding system. This according to our opinion managed to remove the bias of the coding defect of our Trust and provide an objective view of the cost-effectiveness of the follow-up. Even though the cost of single acts for private patients is higher than that of National Health System patients, the private patient coding is more standardized and, considering that our objective was to compare the relative costs, this offered us a trustful result.

\section{Results}

The final sample consisted of 192 patients with a median age of 42.72 years (range 19-79 years). Epidemiologic outcomes evidenced that $74.5 \%$ of our patients (n $=143)$, were male, while $25.5 \%(n=49)$ were females. $82.3 \%$ of our patients were presented with a single ure- 
Table 3b. Cost analysis per follow-up parameters-Bivariate Pearson's

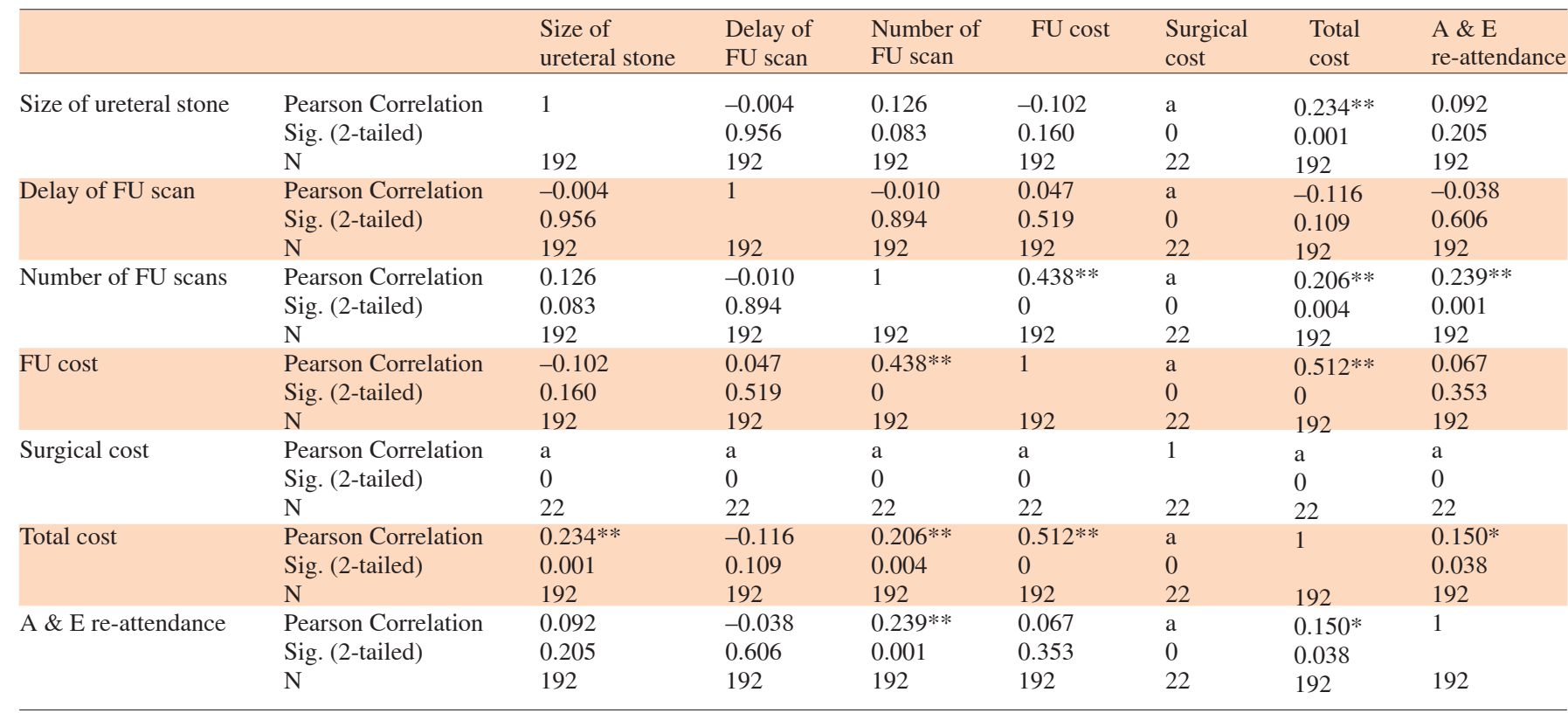

$\mathrm{a}=$ Cannot be computed because at least one of the variables is constant; **. Correlation is significant at the 0.01 level (2-tailed); *. Correlation is significant at the 0.05 level (2-tailed). $\mathrm{FU}=$ follow-up.

Table 4a. Cost analysis per outcome

\begin{tabular}{llllll}
\hline Outcome & $\mathrm{N}$ & \multicolumn{4}{c}{ Subset for alpha $=0.05$} \\
\cline { 2 - 5 } & 1 & 2 & 3 & 4 & 1 \\
\hline Expulsion & 169 & 764.24 & & & \\
Ureteroscopy & 3 & & 986.33 & & \\
Ureteral stent & 10 & & & 1245.60 & \\
Ureterolithotripsy & 8 & & & 1350.75 & \\
ESWL & 2 & & & & 1604.33 \\
Sig. & & 1.000 & 1.000 & 0.335 & 1.000 \\
& & & & &
\end{tabular}

$\mathrm{ESWL}=$ Extracorporeal shock wave lithotripsy.

teral stone, while $12 \%$ of the patients had one additional renal stone, and $5.7 \%$ had more than one additional renal stone. The mean size of the ureteral stone was $4.65 \mathrm{~mm}$ (1.6-9 mm, SD $1.65 \mathrm{~mm}$ ). The majority of the ureteral stones $(42.7 \%$ ) were sized 4-6 mm (table 2).

Comparing male and female groups on the parameters examined (stone size, stone position, degree of dilatation, number of stones, number of re-attendances to $\mathrm{A}$ $\&$ E, and estimated cost), the only significant differences found were those related to the number of stones and to

Clinical and Cost-effectiveness of Conservative Management of Small Ureteral Stones
Table 4b. Cost analysis per outcome

\begin{tabular}{llrccc}
\hline & $\begin{array}{l}\text { Outcome in } \\
\text { 2 categories }\end{array}$ & N & Mean & $\begin{array}{l}\text { Standard } \\
\text { deviation }\end{array}$ & $\begin{array}{l}\text { Std. error } \\
\text { mean }\end{array}$ \\
\hline $\begin{array}{l}\text { Total Cost } \\
(\mathfrak{f})\end{array}$ & Expulsion & 169 & 764,24 & 148,768 & 11,444 \\
& Surgery & 23 & 1317,39 & 352,703 & 73,544 \\
\hline
\end{tabular}

the degree of dilatation. Male patients had double chances (20.3 vs. $10.3 \%)$ to present additional renal stones, apart from their ureteral one, whilst female patients were more likely to have moderate (26.5 vs. $21.7 \%$ ) or severe(4.1 vs. $0 \%$ ) hydronephrosis.

Stone size was independently related to the degree of hydronephrosis (Pearson bivariate correlation, sig = $0.003, \mathrm{p}<0.01)$.

In the selected patients, $169(88 \%)$ were successful with MET, while 23 (12\%) had surgical treatment because of persistence of the ureteral stone. Patients with larger ureteral stones had a greater chance of requiring a surgical procedure (fig. $1, \mathrm{p}<0.05$ ).

The mean delay of the follow-up scan was found to be bigger (52.77 vs. 34.7 days) for the "expulsion" group. The mean delay of follow-up scans for the entire group 
Table 4c. Total costs $(£)$ per outcome-stone size/calculation of cost benefit

\begin{tabular}{llll}
\hline & & Stone size & \\
\cline { 2 - 4 } & $0-3.99 \mathrm{~mm}(\mathrm{n}=53)$ & $4-5.99 \mathrm{~mm}(\mathrm{n}=82)$ & $6-10 \mathrm{~mm}(\mathrm{n}=57)$ \\
\hline Expulsion $(\mathrm{n}=169)$ & $\sum=38976.24(\mathrm{n}=51)$ & $\sum=58082.24(\mathrm{n}=76)$ & $\sum=32098.08(\mathrm{n}=42)$ \\
Surgery $(\mathrm{n}=23)$ & $\sum=2634.78(\mathrm{n}=2)$ & $\sum=7904.34(\mathrm{n}=6)$ & $\sum=19760.85(\mathrm{n}=15)$ \\
Total & $\sum=41611.02$ & $\sum=65986.58$ & $\sum=51858.93$ \\
Total if early surgery & $\sum=56852.57$ & $\sum=87960.58$ & $\sum=61143.33$ \\
Cost benefit of conservative treatment & $26.8 \%$ & $25 \%$ & $15.2 \%$
\end{tabular}

of patients was 50.6 days, with $91.7 \%$ of the patients having 1 follow-up scan, $6.8 \%$ needing an additional one, and 3 patients (1.6\%) in need of 3 different FU scans. The biggest part of the patients (55.21\%), were followed up with a single ultrasound scan KUB.

The mean follow-up scan cost was $244.70 £$ (99-734 $£)$. The follow-up cost was found to be related to the type of follow-up scans used, but also to their efficiency, thus scans that may cost less as single examinations were found to be more cost-weighted if additional scans were required (table $3 a, p<0.05$ ). Having performed an additional correlation of follow up parameters (follow-up scans number, follow-up scans cost, follow-up delay, A $\& \mathrm{E}$ attendance), we demonstrated that there is a strong correlation, not only between the follow-up cost and the number of follow-up scans, but also between the total cost and the number of FU scans (table $3 b, p<0.01$ ), and the number of $\mathrm{A} \& \mathrm{E}$ attendances (table $3 \mathrm{~b}, \mathrm{p}<0.05$ ). There was as well a correlation of the number of the A $\& \mathrm{E}$ attendances to the number of follow-up scans (table $3 \mathrm{~b}, \mathrm{p}<0.01$ ), but not directly to the follow-up cost. The ureteral stone size was significantly correlated only to the total cost per patient (table $3 b, p<0.01$ ). There was no strong correlation between the surgical cost with any of the parameters analyzed (table $3 b, p<0.01, p<0.05$ ).

The mean total cost per patient was $830.53 £(515-$ $2,064 £$ ). Patients of the "expulsion" group had a mean cost of $764.24 £$, while the patients who had to be operated, had a mean total cost of 1,317.39 £ (table 4a and $4 \mathrm{~b}, \mathrm{p}<0.05)$. Having estimated the cost effectiveness of the conservative follow up per individual groups, the out -coming cost benefit was comparable for the first 2 stone size groups, being $26.8 \%$ and $25 \%$ for the group $0-4 \mathrm{~mm}$ and $4-6 \mathrm{~mm}$ respectively, while it was $17.32 \%$ for the group of patients with a ureteral stone $6-10 \mathrm{~mm}$ in size (table 4c).

\section{Discussion}

Male patients, who were the predominant sample, in concordance to the epidemiology urolithiasis [30], had also double chances for additional renal stones. Interestingly female patients scored slightly worse hydronephrosis.

Patients with ureteral stones of 6-10 $\mathrm{mm}$ had $22.5 \%$ greater chance of requiring surgical management, compared to the group of patients with stones of $0-4 \mathrm{~mm}$. The total rate of expulsion of stones $\leq 10 \mathrm{~mm}$ was $88 \%$, while in the group of $<4 \mathrm{~mm}$, expulsion rate was $96.2 \%$.

No stratification per stone position was made. This is a limitation of this study, though the management of proximal and distant ureteral stones shouldn't be different [9].

In our patients $90.1 \%$ were successfully followed-up with a single follow-up scan. In more than $55 \%$ of the cases this was a single USS KUB, as only $18.2 \%$ of our patients did not have any degree of dilatation on presentation. In less than $15 \%$ of our group an additional CT KUB was required. The number of follow-up scans performed was found to be related to the number of A \& E re-attendances. Indeed, most of the patients who returned to A \& E due to pain were re-scanned. On the contrary, the number of follow-up scans was not directly related to the stone size; the same is valid for the A \& E re-attendances. Thus, patients with bigger stones do not require more scans for their follow-up, nor have more episodes of renal colic.

The mean follow-up scan delay was found to be shorter by 18 days in the group of patients that had surgical management and was shorter for patients with bigger stones, which is in concordance with their bigger chances to have surgical treatment and the need of closer monitor. 


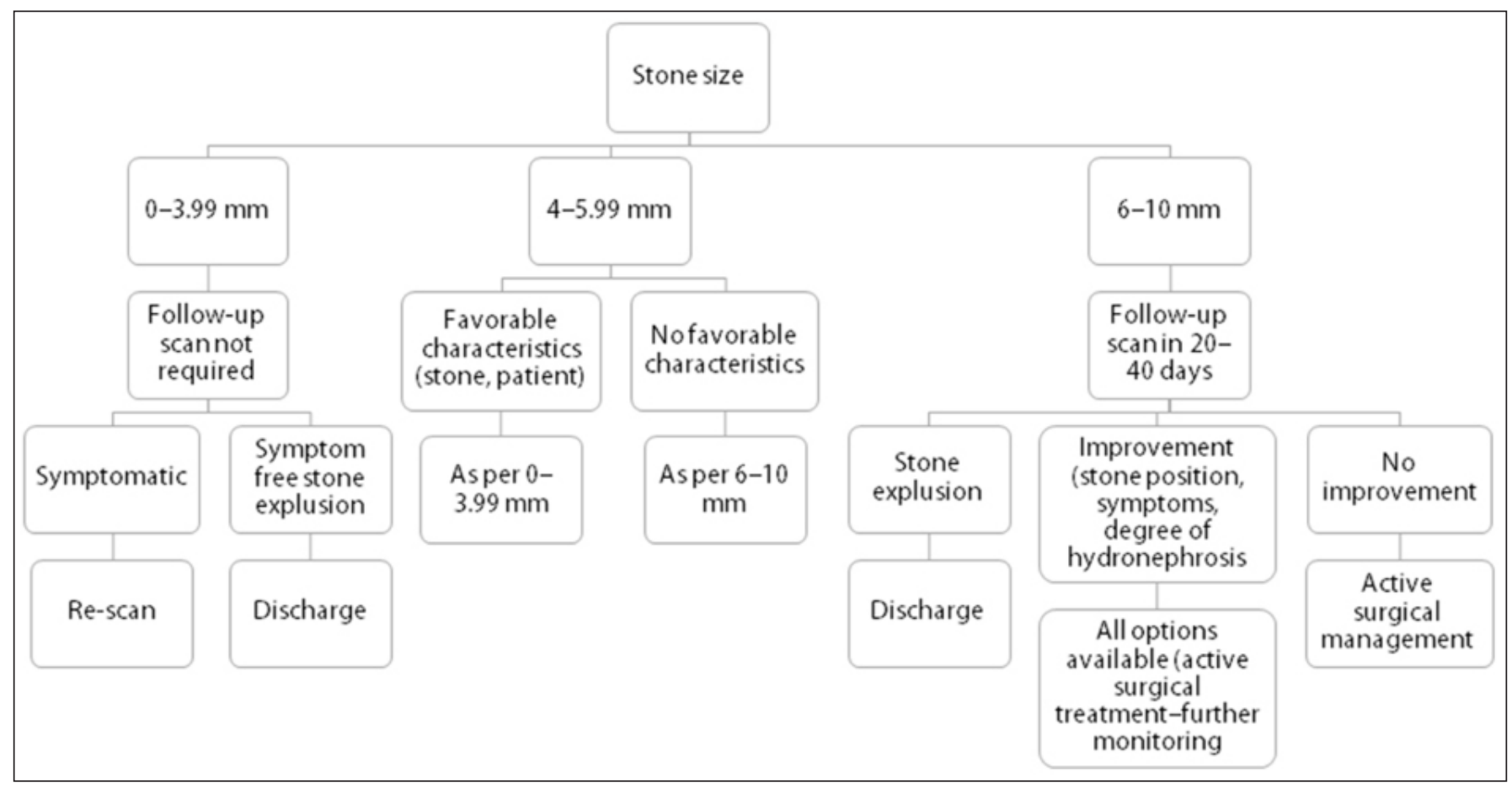

Fig. 2. Suggested algorithm for the management of single ureteric stones $\leq 10 \mathrm{~mm}$.

Regarding the clinical outcome of MET, the group of ureteral stones of 0-4 $\mathrm{mm}$ had an impressive expulsion rate of $>96 \%$, generating doubts on the need of follow-up scans within protocol for this group. For the group of patients with stones of $6-10 \mathrm{~mm}$ the expulsion rate was as high as $73.7 \%$, whereas in the group of 4-6 mm this was $92.7 \%$ (fig. 1).

From our cost analysis, we saw that the cost of the follow-up was related to the number and type of scans used, but also to their efficiency. Thereby, the use of $\mathrm{x}$-ray KUB as a single diagnostic instrument was less cost-effective compared to the use of the intravenous urogram, due to the bigger need for additional scans (table $3 a)$. The total cost per patient was related to the number and cost of follow-up scans, but also to the ureteral stone size. That means that patients with bigger ureteral stones tend to cost more. The cost of surgery was not found to be related to any of the parameters.

We found that the mean total cost for the "expulsion" group patients was smaller by almost $42 \%$, compared to the cost of the group that had surgery (764.24 vs. $1,317.39$ f). The difference on the cost of the above 2 groups is generated by the cost of surgery, as all our patients were initially on a conservative protocol. Trying to investigate on the cost effectiveness of this, we compared our actual total cost to the one that would have come out if all our patients were treated with early surgery, avoiding the additional follow-up cost. We therefore divided the real total cost per stone size category with the hypothetical cost of early surgery. This way we managed to demonstrate that surveillance with follow up scans is cost effective, not only for the groups with smaller stones, but also for the group of 6-10 mm, which has $26.3 \%$ chances to end up with surgical management. In this particular group the cost benefit was $15.2 \%$.

\section{Conclusions}

Our main findings regarding the natural history of the ureteral stone sized $\leq 10 \mathrm{~mm}$ are that indeed bigger stones cause bigger degree of hydronephrosis, and are less likely to be expelled with conservative management; in contrary they are not related to bigger amount of pain (A \& E re-attendances). This is an outcome which hasn't been noted previously.

With regards to follow-up of our patients the single ultrasound scan KUB was found to be sufficient as a follow-up scan in more than $55 \%$ of the cases. 
Considering the clinical effectiveness, patients with a stone of up to $4 \mathrm{~mm}$ were successful with conservative management in over $96 \%$ of the cases, and this puts the usefulness of follow up scans in dispute for a particular group of these patients. Our suggestion would be that at least young, healthy and active patients within this group, could be monitored based on their symptoms. This strategy would minimize the total cost of follow-up, as well as the mean follow-up scan delay, benefiting patients in need of strict follow-up. Symptom monitoring could also be considered for some selected patients of the group of 4-6 $\mathrm{mm}$, based on the stone features (position, shape), and the patient characteristics (age, mobility, co-morbidities, residence, performance status) and symptoms (fig. 2).

Another original outcome of the study was that conservative management was found to be cost-effective in all the size subgroups, scoring a cost-benefit of over $15 \%$ for the most challenging group of ureteral stones sized 6-10 mm.

The clinician though who assesses patients with ureteral stones of 6-10 $\mathrm{mm}$, has to underline that they have more than $26 \%$ of chances to end up with a surgical management. Additionally, this study evidenced that patients with bigger ureteral stones, within the limits of $10 \mathrm{~mm}$ should not suffer from more significant pain during their follow-up, compared to patients with smaller stone sizes.

Concluding, this study supports the clinical and cost-effectiveness of conservative management vs early surgery for ureteral stones $\leq 10 \mathrm{~mm}$, creating also some space for modifications of the way to follow-up these patients, based on their stone size.

\section{Limitations}

There wasn't any consideration of the stone position in relation to the stone's main axis and to the ureteral axis. As known, the stone shape and position in the ureter is important in estimating the likelihood of the stone passage, particularly for stones $>6 \mathrm{~mm}$. The Hounsfield units of the ureteral stones were not considered in this study, as they are not a weighting parameter in opting for conservative management or early surgery, while no stratification per stone position was made.

The use of re-admissions to A \& E as a tool of measurement of pain level provides a less direct measurement, compared to pain rating systems, such as the visual analogue scale. Though, it was the most reliable tool within the current setup of this study, providing also information regarding the economic features of the pain level.

\section{Declarations}

Contributorship: A.A. and D.Z. have collected the data. M.H. and K.C. provided concept and initial design of the paper. A.P. has performed the statistical and economic analysis. A.A has written and finalized the paper.

Acknowledgements: The authors would like to thank Mr. R. Dasgupta who has kindly reviewed the article. 


\section{References}

1 Preminger GM, Tiselius HG, Assimos DG, Alken P, Buck AC, Gallucci M, Knoll T, Lingeman JE, Nakada SY, Pearle MS, Sarica K, Türk C, Wolf JS Jr: 2007 Guideline for the management of ureteral calculi. Eur Urol 2007;52:1610-1631.

2 Eisner BH, Reese A, Sheth S, Stoller ML: Ureteral stone location at emergency room presentation with colic. J Urol 2009;182:165168.

3 Goertz JK, Lotterman S: Can the degree of hydronephrosis on ultrasound predict kidney stone size? Am J Emerg Med 2010;28:813816.

4 Al-Ansari A, Al-Naimi A, Alobaidy A, Assadiq K, Azmi MD, Shokeir AA: Efficacy of tamsulosin in the management of lower ureteral stones: a randomized double-blind placebo-controlled study of 100 patients. Urology 2010;75:4-7.

5 Liatsikos EN, Katsakiori PF, Assimakopoulos K, Voudoukis T, Kallidonis P, Constantinides C, Athanasopoulos A, Stolzenburg JU, Perimenis P: Doxazosin for the management of distal-ureteral stones. J Endourol 2007;21:538-541.

6 Porpiglia F, Vaccino D, Billia M, Renard J, Cracco C, Ghignone G, Scoffone C, Terrone C, Scarpa RM: Corticosteroids and tamsulosin in the medical expulsive therapy for symptomatic distal ureter stones: single drug or association? Eur Urol 2006;50:339-344.

7 Yilmaz E, Batislam E, Basar MM, Tuglu D, Ferhat M, Basar H: The comparison and efficacy of 3 different alpha1-adrenergic blockers for distal ureteral stones. J Urol 2005;173: 2010-2012.

8 Hermanns T, Sauermann P, Rufibach K, Frauenfelder T, Sulser T, Strebel RT: Is there a role for tamsulosin in the treatment of distal ureteral stones of $7 \mathrm{~mm}$ or less? Results of a randomised, double-blind, placebo-controlled trial. Eur Urol 2009;56:407-412.

9 Yencilek F, Erturhan S, Canguven O, Koyuncu H, Erol B, Sarica K: Does tamsulosin change the management of proximally located ureteral stones? Urol Res 2010;38:195-199.

10 Pickard R, Starr K, MacLennan G, Lam T, Thomas R, Burr J, McPherson G, McDonald A, Anson K, N'Dow J, Burgess N, Clark T, Kilonzo M, Gillies K, Shearer K, Boachie C, Cameron S, Norrie J, McClinton S: Medical expulsive therapy in adults with ureteric colic: a multicentre, randomised, placebocontrolled trial. Lancet 2015;386:341-349.
11 Johnston R, Lin A, Du J, Mark S: Comparison of kidney-ureter-bladder abdominal radiography and computed tomography scout films for identifying renal calculi. BJU Int 2009;104:670-673.

12 Macejko A, Okotie OT, Zhao LC, Liu J, Perry K, Nadler RB: Computed tomography-determined stone-free rates for ureteroscopy of upper-tract stones. J Endourol 2009;23:379382.

13 Kalra MK, Maher MM, D'Souza RV, Rizzo S, Halpern EF, Blake MA, Saini S: Detection of urinary tract stones at low-radiation-dose CT with z-axis automatic tube current modulation: phantom and clinical studies. Radiology 2005;235:523-529.

14 Oner S, Oto A, Tekgul S, Koroglu M, Hascicek M, Sahin A, Akhan O: Comparison of spiral CT and US in the evaluation of pediatric urolithiasis. JBR-BTR 2004;87:219-223.

15 Yang M, Gao F, Liu H, Pang H, Zuo YP, Yong T: Prospectively estimating the recoverability of renal function after relief of unilateral urinary obstruction by measurement of renal parenchymal volume. Acad Radiol 2013;20: 401-406.

16 Chaabane W, Praddaude F, Buleon M, Jaafar A, Vallet M, Rischmann P, Galarreta CI, Chevalier RL, Tack I: Renal functional decline and glomerulotubular injury are arrested but not restored by release of unilateral ureteral obstruction (UUO). Am J Physiol Renal Physiol 2013;304:F432-439.

17 Ravanan R, Tomson CR: Natural history of postobstructive nephropathy: a single-center retrospective study. Nephron Clin Pract 2007; 105:c165-170.

18 Huland H, Gonnermann D, Leichtweiss HP, Dietrich-Hennings R: Reversibility of preglomerular active vasoconstriction in the first weeks after complete unilateral ureteral obstruction by inhibition of prostaglandin synthesis. J Urol 1983;130:820-824.

19 Ito K, Chen J, El Chaar M, Stern JM, Seshan SV, Khodadadian JJ, Richardson I, Hyman MJ, Vaughan ED Jr, Poppas DP, Felsen D: Renal damage progresses despite improvement of renal function after relief of unilateral ureteral obstruction in adult rats. Am J Physiol Renal Physiol 2004;287:F1283-1293.

20 Bagrodia A, Gupta A, Raman JD, Bensalah K, Pearle MS, Lotan Y: Predictors of cost and clinical outcomes of percutaneous nephrostolithotomy. J Urol 2009;182:586-590.
21 Cone EB, Eisner BH, Ursiny M, Pareek G: Cost-effectiveness comparison of renal calculi treated with ureteroscopic laser lithotripsy versus shockwave lithotripsy. J Endourol 2014;28:639-643.

22 Cui Y, Cao W, Shen H, Xie J, Adams TS, Zhang Y, Shao Q: Comparison of ESWL and ureteroscopic holmium laser lithotripsy in management of ureteral stones. PLoS One 2014;9:e87634.

23 Hyams ES, Shah O: Percutaneous nephrostolithotomy versus flexible ureteroscopy/ holmium laser lithotripsy: cost and outcome analysis. J Urol 2009;182:1012-1017.

24 Izamin I, Aniza I, Rizal AM, Aljunid SM: Comparing extracorporeal shock wave lithotripsy and ureteroscopy for treatment of proximal ureteric calculi: a cost-effectiveness study. Med J Malaysia 2009;64:12-21.

25 Knoll T, Fritsche HM, Rassweiler J: Medical and economic aspects of extracorporeal shock wave lithotripsy. Aktuelle Urol 2011; 42:363-367.

26 Koo V, Young M, Thompson T, Duggan B: Cost-effectiveness and efficiency of shockwave lithotripsy vs flexible ureteroscopic holmium: yttrium-aluminium-garnet laser lithotripsy in the treatment of lower pole renal calculi. BJU Int 2011;108:1913-1916.

27 Matlaga BR, Jansen JP, Meckley LM, Byrne TW, Lingeman JE: Economic outcomes of treatment for ureteral and renal stones: a systematic literature review. J Urol 2012;188: 449-454.

28 Bensalah K, Pearle M, Lotan Y: Cost-effectiveness of medical expulsive therapy using alpha-blockers for the treatment of distal ureteral stones. Eur Urol 2008;53:411-418.

29 Hollingsworth JM, Norton EC, Kaufman SR, Smith RM, Wolf JS, Hollenbeck BK: Medical expulsive therapy versus early endoscopic stone removal for acute renal colic: an instrumental variable analysis. J Urol 2013;190: 882-887.

30 Trinchieri A: Epidemiology of urolithiasis: an update. Clin Cases Miner Bone Metab 2008;5:101-106. 